\title{
STUDI SIMULASI BIAYA OPERASI DAN PEMELIHARAAN JARINGAN IRIGASI AIR TANAH UNTUK MENDAPATKAN HASIL PRODUKSI PERTANIAN YANG OPTIMAL (STUDI KASUS JIAT TW 017 R DAN PWS 231 DI KECAMATAN KALIJAMBE KABUPATEN SRAGEN)
}

\author{
Agus Hari Wahyudi', Adi Yusuf Muttaqien ${ }^{2}$, dan Rn Claresta Vania ${ }^{3}$ \\ 1) Pengajar Fakultas Teknik, Prodi Teknik Sipil, Universitas Sebelas Maret \\ 2) Pengajar Fakultas Teknik, Prodi Teknik Sipil, Universitas Sebelas Maret \\ 3) Mahasiswa Fakultas Teknik, Prodi Teknik Sipil, Universitas Sebelas Maret \\ Jl. Ir. Sutami 36A, Surakarta 57126; Telp. 0271-634524. Email: clarestavania9@ gmail.com
}

\begin{abstract}
Indonesia is an agrarian country, most of the population earns a living as farmers. Management of irrigation water networks, which are included in operating and maintenance costs, is important in supporting agricultural success. So research is needed to analyze the effect of OP costs on agricultural production, namely the duration of pump operation of groundwater irrigation networks to obtain the optimum benefit cost ratio. This study was carried out at pump wells TW 017 and PWS 231 located in Kalijambe District, Sragen Regency. The initial stage in this study is calculating the water requirements in the fields to obtain a K factor value (availability / needed). From the K factor, the size of agricultural products is obtained. After that, calculate the amount of OP costs according to several alternative pump operating hours. Then calculate the BCR value, so that we get the value of pump operating hours is obtained per day which makes the optimum BCR value. From the graph of the relationship between pump operating hours and BCR values, the results obtained at pump $T W 017 \mathrm{R}$ pump hours of operation which produces the optimum BCR value is the pump operating hours of 11,903 hours / day, with a BCR value of 1,949. While the PWS 231 pump hours of operation which produces the optimum $B C R$ value is the pump operating hours of 12,168 hours / day, with a BCR value of 2,23.
\end{abstract}

Keywords: JLAT, K factor, pump operating hours, Benefit Cost Ratio (BCR).

\begin{abstract}
Abstrak
Indonesia merupakan negara agraris, sebagian besar penduduknya bermata pencaharian sebagai petani. Sehingga pengelolaan jaringan air irigasi, yang termasuk dalam biaya operasi dan pemeliharaan merupakan hal penting dalam menunjang keberhasilan pertanian. Maka diperlukan adanya penelitian untuk menganalisa pengaruh biaya OP terhadap hasil produksi pertanian, yaitu lamanya operasi pompa jaringan irigasi air tanah untuk mendapatkan nilai benefit cost ratio yang optimum. Studi ini dilakukan pada sumur pompa TW 017 dan PWS 231 yang terletak di Kecamatan Kalijambe Kabupaten Sragen. Tahap awal dalam studi ini dengan menghitung kebutuhan air di sawah untuk mendapatkan nilai Faktor K (ketersedian/kebutuhan). Dari Faktor K, maka didapat besarnya hasil pertanian. Setelah itu menghitung besarnya biaya OP sesuai dengan beberapa alternatif lama waktu operasi pompa. Lalu menghitung nilai BCR, sehingga didapatkan nilai lama waktu operasi pompa per hari yang membuat nilai BCR optimum. Dari grafik hubungan antara lama waktu operasi pompa dengan nilai BCR, didapatkan hasil pada pompa TW 017 R lama waktu operasi yang menghasilkan nilai BCR optimum adalah lama waktu operasi pompa selama 11,903 jam/hari,dengan nilai BCR 1,949. Sedangkan pada Pompa PWS 231 lama waktu operasi yang menghasilkan nilai BCR optimum adalah lama waktu operasi pompa 12,168 jam/hari, dengan nilai BCR 2,23.
\end{abstract}

Kata Kunci : JIAT, faktor K, lama waktu operasi pompa, Benefit Cost Ratio (BCR).

\section{PENDAHULUAN}

Indonesia merupakan negara agraris yang sebagian besar penduduknya memiliki mata pencaharian melalui sektor pertanian. Pengelolaan air irigasi merupakan hal penting untuk menunjang keberhasilan pertanian, salah satu alternatif untuk kebutuhan air irigasi adalah air tanah Wilayah Indonesia sendiri memiliki potensi air tanah yang sangat besar, terdiri dari 5.560 buah jaringan dengan luas potensial sebesar 113.600 ha yang tersebar di seluruh wilayah Indonesia (Permen PUPR No 14 tahun 2015). Di daerah DAS Bengawan Solo sendiri terdapat cukup banyak sebaran Jaringan Irigasi Air Tanah, diantaranya tersebar di Kabupaten Sragen yang memiliki sumber daya air tanah sebesar 137 juta m3/tahun. Air tanah yang tersedia di Kabupaten Sragen dikembangkankan menjadi jaringan irigasi air tanah untuk memenuhi kebutuhan air pada daerah layanan irigasi di Kabupaten Sragen. Studi ini dilakukan pada sumur pompa TW 017 R (pompa turbin vertikal) dan PWS 231 (pompa submersibel) yang terletak di Kecamatan Kalijambe Kabupaten Sragen, Provinsi Jawa Tengah.

Ketersediaan biaya operasi dan pemeliharaan menjadi faktor utama suatu jaringan irigasi. Jika tidak dilakukan pengelolaan operasional yang baik, maka hasil produksi pertanian akan menurun. Sejalan dengan hal tersebut maka 
diperlukan adanya penelitian untuk menganalisa pengaruh besarnya biaya operasi dan biaya pemeliharaan terhadap hasil produksi pertanian. Penelitian ini menggunakan studi simulasi untuk mencari lamanya lama waktu operasi pompa jaringan irigasi air tanah agar didapatkan nilai benefit cost ratio yang optimum sehingga memaksimalkan hasil pertanian.

\section{LANDASAN TEORI}

Peraturan Menteri Pekerjaan Umum dan Perumahan Rakyat Republik Indonesia Nomor 14/PRT/M/2015, jaringan irigasi air tanah adalah jaringan irigasi yang airnya berasal dan air tanah, mulai dari sumur dan instalasi pompa sampai dengan saluran irigasi air tanah termasuk bangunan di dalamnya. Berdasarkan Laporan Penilaian Kinerja dan Penyusunan AKNOP JIAT Bengawan Solo Tahun 2017, pada kondisi lapangan yang menjadi komponen utama jaringan irigasi air tanah adalah sumur dan mesin pompa. Faktor yang menentukan keberlangsungan beroperasinya sumur pompa adalah biaya pengelolaan yang terdiri dari biaya untuk operasi dan pemeliharaan sumur pompa, serta biaya penggantian irigasi sumur pompa. Ada beberapa komponen biaya dan pemeliharaan sumur pompa yaitu biaya bahan bakar, biaya pemeliharaan sumur pompa, biaya penunjang organisasi dan personalia.

Sedangkan untuk mencari kebutuhan air di sawah dilakukan beberapa perhitungan, seperti mencari nilai curah hujan efektif yang tersedia untuk kebutuhan air tanaman, mencari nilai evapotranspirasi yang membutuhkan data klimatologi, setelah itu mencari nilai kebutuhan air selama penyiapan lahan dengan perhitungan yang dikembangkan oleh Van de Goor dan Zijlstra, setelah itu menentukan kebutuhan air disawah setiap bulan sesuai dengan rencana pola tanam yang diterapkan. Menurut Bonita (2015) untuk perhitungan keseimbangan air (faktor K), faktor yang berpengaruh adalah adalah ketersediaan air dari aliran air tanah (didasarkan dari lamanya pompa beroperasi) dan kebutuhan air dari tiap daerah layanan (kebutuhan air tanah sendiri untuk industri domestik serta irigasi persawahan). Nilai faktor $\mathrm{K}$ ini untuk mendapatkan besarnya hasil pertanian sesuai dengan persamaan yang di dapat dari grafik hubungan hasil pertanian dengan pemenuhan kebutuhan air.

Menurut Raharjo (2007) analisis Benefit Cost Ratio (BCR) adalah perbandingan nilai ekuivalen semua manfaat terhadap nilai ekuivalen semua biaya, dengan rumus sebagai berikut:

$B C R=\frac{\frac{\text { benefit }}{(1+i)^{t}}}{\frac{\cos t}{(1+i)^{t}}}$.

keterangan :

Benefit $=$ Keuntungan total yang diterima masyarakat

Cost $=$ Biaya total yang dikeluarkan untuk membiayai proyek

$\mathrm{i} \quad=$ Suku bunga $(\%)$

$\mathrm{t}=$ Kurun waktu (tahun)

\section{METODE}

Metode yang digunakan dalam penelitian ini adalah metode studi simulasi. Tahapan penelitian meliputi tahap persiapan dengan studi pustaka dan melakukan pengumpulan data sekunder seperti data curah hujan, data klimatologi, data spesifikasi pompa yang didapat dari survey lokasi, data harga upah serta bahan. Untuk mencari nilai BCR optimum, dibuat beberapa alternatif lama waktu operasi pompa per hari sesuai jenis pompa masingmasing. kegiatan pengumpulan data primer dimulai dengan melakukan perhitungan kebutuhan air irigasi sesuai rencana pola tanam di sekitar lokasi (padi-padi-palawija), lalu perhitungan hasil pertanian dari nilai keseimbangan air (faktor K), perhitungan biaya operasi dan pemeliharaan jaringan irigasi air tanah menurut Permen PU. No.11/PRT/M/2013, perhitungan analisis ekonomi dengan perhitungan BCR, dan terakhir dengan membuat grafik hubungan antara nilai BCR dengan lama waktu operasi pompa.

\section{HASIL DAN PEMBAHASAN}

Berdasarkan hasil analisa yang telah dilakukan, penelitian ini bertujuan untuk mendapatkan nilai lama waktu operasi pompa per hari agar mendapatkan nilai BCR optimum. Dari hasil perhitungan BCR, pada pompa TW 017 R lama waktu operasi per hari yang menghasilkan nilai BCR optimum adalah lama waktu operasi pompa selama 17,44 jam/hari,dengan nilai BCR 3,74. Sedangkan pada Pompa PWS 231 lama waktu operasi yang menghasilkan nilai BCR optimum adalah lama waktu operasi pompa selama 10,12 jam/hari, dengan nilai BCR 2,89.

Hasil hubungan antara lama waktu operasi pompa per hari dengan nilai BCR pada pompa TW 017 R dapat dilihat pada Tabel 1 
Tabel 1. Hubungan Antara Lama waktu operasi Pompa Dengan Nilai BCR Pada Sumur Pompa TW 017 R

\begin{tabular}{lll}
\hline No. & $\begin{array}{l}\text { Alternatif Lama Waktu Operasi } \\
\text { (jam/hari) }\end{array}$ & Nilai BCR \\
\hline 1. & 10 & 1,94 \\
\hline 2. & 12,5 & 1,97 \\
\hline 3. & 15 & 1,93 \\
\hline 4. & 17,5 & 1,86 \\
\hline 5. & 20 & 1,77 \\
\hline
\end{tabular}

Grafik hubungan antara lama waktu operasi pompa per hari dengan nilai BCR pada pompa TW 017 R dapat dilihat pada Gambar 1

\section{Sumur Pompa TW 017 R}

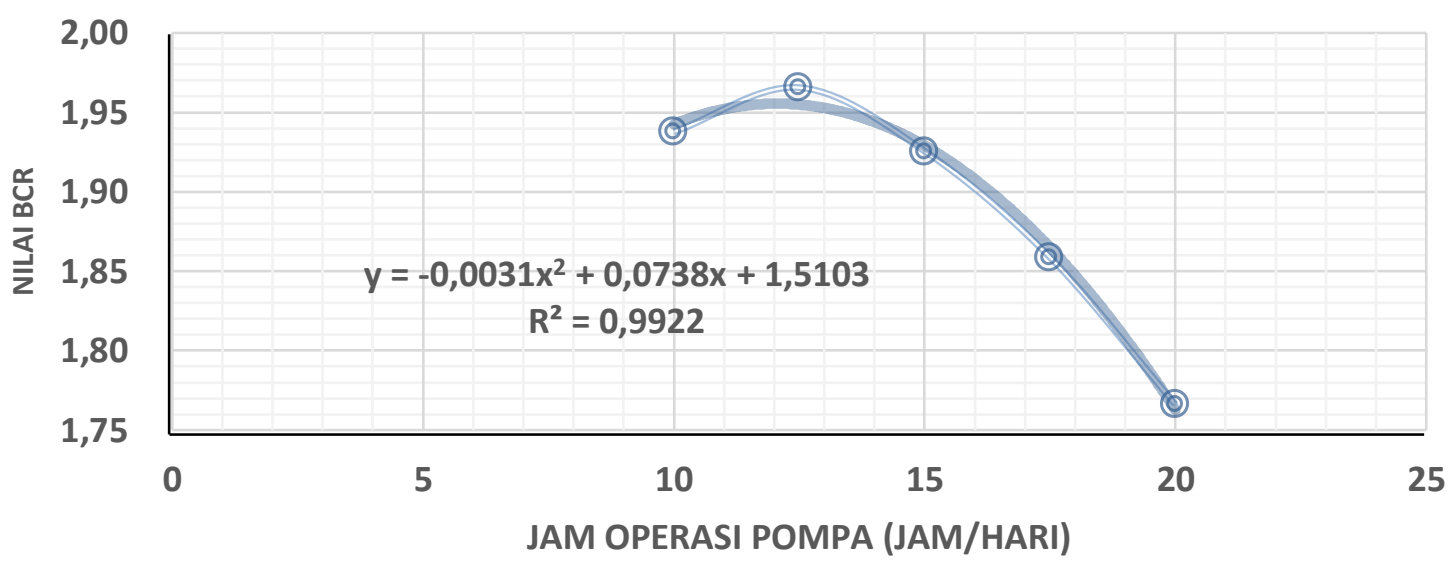

Gambar 1. Grafik Hubungan Antara Lama Waktu Operasi Pompa Dengan Nilai BCR Pada Sumur Pompa TW $017 \mathrm{R}$

Hasil hubungan antara lama waktu operasi pompa per hari dengan nilai BCR pada pompa PWS 231 dapat dilihat pada Tabel 2

Tabel 2. Hubungan Antara Lama waktu operasi Pompa Dengan Nilai BCR Pada Sumur Pompa PWS 231

\begin{tabular}{lll}
\hline No. & $\begin{array}{l}\text { Alternatif Lama Waktu Operasi } \\
\text { (jam/hari) }\end{array}$ & Nilai BCR \\
\hline 1. & 5 & 1,76 \\
\hline 2. & 7,5 & 2,08 \\
\hline 3. & 10 & 2,22 \\
\hline 4. & 12,5 & 2,20 \\
\hline 5. & 15 & 2,12 \\
\hline 6. & 17,5 & 2,02 \\
\hline
\end{tabular}

Grafik hubungan antara lama waktu operasi pompa per hari dengan nilai BCR pada pompa PWS 231 dapat dilihat pada Gambar 2 


\section{Sumur Pompa PWS 231}

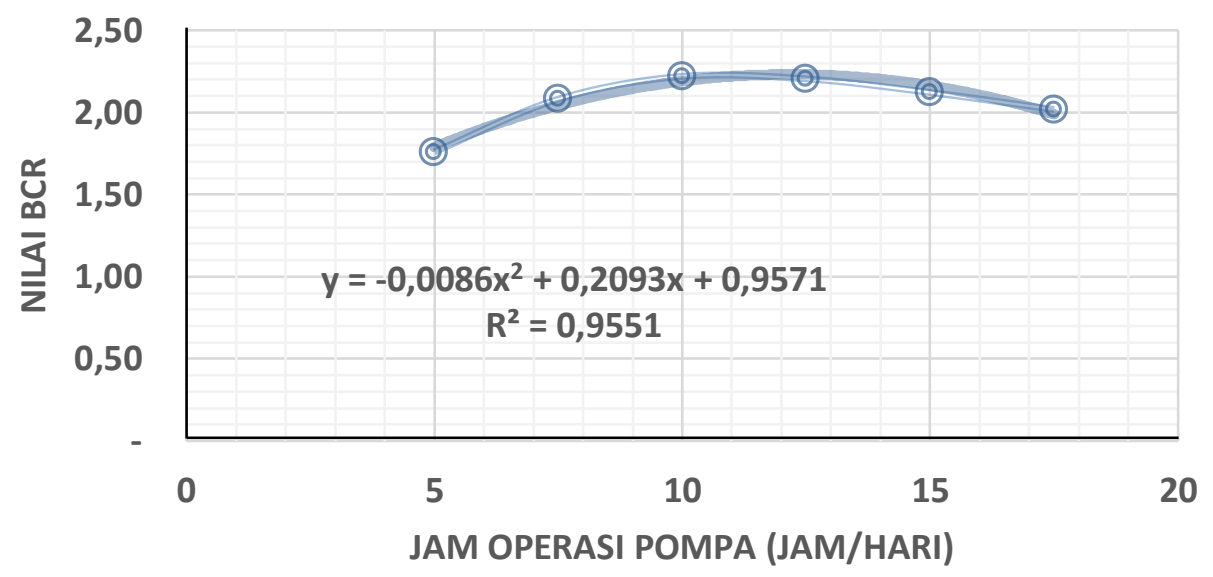

Gambar 2. Grafik Hubungan Antara Lama Waktu Operasi Pompa Dengan Nilai BCR Pada Sumur Pompa PWS 231

\section{SIMPULAN}

Komponen dominan yang menentukan keberhasilan operasi dan pemeliharaan Jaringan Irigasi Air Tanah adalah prasarana fisik (sumur, mesin pompa, mesin genset/mesin penggera, rumah pompa), faktor produktifitas tanam terdiri dari pemenuhan akan kebutuhan air, luas tanam dan produktifitas tanaman seperti palawija dan padi, sarana penunjang yang diperlukan untuk menunjang pengoperasian jaringan irigasi air tanah agar lebih efektif dan efisien. Variabel yang paling berpengaruh terhadap biaya operasi dan pemeliharaan jaringan irigasi air tanah adalah lamanya operasi pompa. Karena semakin lama lama waktu operasi pompa maka semakin tinggi pula biaya operasi dan pemeliharaan jaringan irigasi air tanahnya. Jika lama waktu operasi pompa JIAT sedikit artinya biaya OP rendah maka penyediaan air nya terbatas dengan demikian hasil produksi pertaniannya rendah. Namun sebaliknya bila lama waktu operasi melebihi kebutuhan air irigasi maka biayanya tinggi tetapi produksi pertaniannya sudah optimal. Berdasarkan hasil analisa yang telah dilakukan, pada pompa TW $017 \mathrm{R}$ didapat nilai BCR optimum 1,949, dengan lama waktu operasi per hari selama 11,903 jam/hari. Pada pompa PWS 231 didapat nilai BCR optimum 2,23, dengan lama waktu operasi per hari selama 12,168 jam/hari.

\section{REKOMENDASI}

1. Untuk perhitungan biaya (cost) bisa dihitung sesuai dengan perencanaan biaya yang terjadi dilapangan secara langsung, dengan memasukan semua biaya yang mempengaruhi besarnya biaya OP JIAT. Sehingga bisa menjadi pembanding dengan hasil penelitian ini dalam menentukan BCR yang optimum.

2. Pada penelitian ini faktor yang mempengaruhi produksi pertanian bagian yang menjadi variabel adalah variasi lama pemberian air irigasi (mempengaruhi faktor $\mathrm{k}$ dan mempengaruhi hasil panen per ha) sedangkan untuk faktor lain seperti bibit, pupuk, hama, dan perawatan diasumsikan konstant. Untuk penelitian selanjutnya variabel yang lain bisa diperhitungkan.

\section{UCAPAN TERIMAKASIH}

Ucapan terima kasih pertama ditujukan kepada Tuhan atas berkat-Nya selama penelitian ini. Selanjutnya kepada Bapak Ir. Agus Hari Wahyudi, M.Sc. dan Bapak Ir. Adi Yusuf Muttaqien, M.T. selaku dosen pembimbing yang telah memberi arahan dan masukan dalam penelitian ini. Selain itu penulis juga berterimakasih kepada kedua orang tua yang selalu mendukung dan memotivasi, serta kepada Heribertus Alvian yang memberi semangat serta membantu dalam penelitian ini. 


\section{REFERENSI}

Ardhie, Hanindya Septian. 2017. Evaluasi Kinerja Jaringan Irigasi Air Tanahdi Sub Das Bengawan Solo Madiun : Universitas Sebelas Maret.

Bonita Riztri, Mardyanto Agus. 2015. Studi Water Balance Air Tanah di Kecamatan Kejayan, Kabupaten Pasuruan, Provinsi Jawa Timur. Jurnal teknik ITS

Burhan, Budi, Suprapto, M., Syafi'i, 2015, “Optimasi Distribusi Air Jaringan Irigasi Air Tanah Daerah Irigasi Magepanda Kabupaten Sikka Propinsi Nusa Tenggara Timur”, Surakarta :Universitas Sebelas Maret.

Lipu, S., Mangitung, D., Anasiru, T., 2016. Operasi Dan Pemeliharaan Jaringan Irigasi Airtanah Melalui Partisipasi Aktif Perkumpulan Petani Pemakai Air Di Sulawesi Tengah 14, 7.

Peraturan Menteri Pekerjaan Umum No. 11/PRT/M/2013 tentang Pedoman Analisis Harga Satuan Pekerjaan Bidang Pekerjaan Umum

Permen PUPR Republik Indonesia Nomor 14 /PRT/M/2015 Tentang Kriteria dan Penetapan Status Daerah Irigasi

Prima Cipta Lestari. 2017. Laporan Penilaian Kinerja Dan Penyusunan AKNOP JLAT Bengawan Solo. Balai Besar Wilayah Sungai Bengawan Solo.

Raharjo Ferianto. 2007. Ekonomi Teknik: Analisis Pengambilan Keputusan. Yogyakarta: CV Andi Offset

Raya Konsultan. 2015. Dokumen Draft Pedoman Tata Cara Penyusunan AKNOP JLAT 2015. Direktorat Sumber Daya Air : Kementrian Pekerjaan Umum.

Raya Konsultan. 2015. Dokumen Draft Pedoman Tata Cara OP JLAT 2015. Direktorat Sumber Daya Air: Kementrian Pekerjaan Umum

Restuanti, Widhie Arzy. 2016. Analisis Perbitungan Biaya Operasi dan Pmeliharaan Irigasi Untuk Mewnjudkan Biaya Jasa Pengelolaan Sumber Daya Air Pada Daerah Iirgasi Delta Brantas

Standar Perencanaan Irigasi, 2013, "Perencanaan Jaringan Irigasi KP- 01”., Kementrian Pekerjaan Umum 